\title{
Comunicación para la salud y pandemia. Modelos y analogías en la COVID-19 desde dos perspectivas en México
}

\section{Communication for health and pandemic. Models and analogies in CovID-19 from two perspectives in Mexico}

Rafael Tonatiuh Ramírez Beltrán*

Universidad Anáhuac México

Av. Universidad Anáhuac núm. 46,

Col. Lomas Anáhuac, C. P. 52786,

Huixquilucan, Estado de México

Editor: Rogelio del Prado Flores

Fecha de recepción: 29 de junio de 2020

Fecha de aceptación: 21 de julio de 2020 rramirez@anahuac.mx

http://orcid.org/0000-0002-1968-9755

https://doi.org/10.36105/stx.2020edespcovid-19.05

\section{RESUMEN}

El propósito es aproximarnos a la comunicación oficial y al de la sociedad civil en la pandemia de COVID-19 en México, situándolo como otro síntoma de crisis ambiental y sanitaria. Es relevante el trabajo al utilizar herramientas de comunicación ambiental y para la salud, dar seguimiento a investigaciones de comunicación para el desarrollo, la salud y el ambiente tratando de integrarlas interdisciplinariamente. Se recuperan elementos contextuales que posibilitan estudiar las pandemias y detenernos en la del 2020. Teóricamente se toman las generaciones de modelos de salud que contrastamos con las metáforas de la pandemia, la forma comunicativa de la información oficial durante 120 días y la recuperación de algunas narrativas que publicó la prensa nacional. El eje central es trabajar con diferentes núcleos de la comunicación como son: la gubernamental, la social, ambiental y de salud. Uno de los principales hallazgos es que la comunicación oficial de los meses iniciales, respaldada con algunas

\footnotetext{
* Doctor en Administración Pública. Miembro del Sistema Nacional de Investigadores (SNI), Nivel I, del Consejo Nacional de Ciencia y Tecnología (Conacyt) en México. Profesor-Investigador de la Facultad de Comunicación e investigador del Centro de Investigación para la Comunicación Aplicada (CICA) de la Universidad Anáhuac México, en la línea de investigación: Realidad social, políticas públicas y comunicación.
} 
políticas públicas, contuvieron el crecimiento acelerado del contagio masivo, pero fueron insuficientes según el relato de la gente.

Palabras clave: pandemia y comunicación, categorías y metáforas, comunicación para la salud, crisis ambiental.

\section{ABST RACT}

The purpose is to approach official communication and that of civil society in the COVID-19 pandemic in Mexico, placing it as another symptom of an environmental and health crisis. The work is relevant when using environmental and health communication tools, monitoring communication research for development, health, +and the environment, trying to integrate them interdisciplinary. Contextual elements are recovered that make it possible to study the pandemics and stop at the 2020 one. Theoretically, the generations of health models that we contrast with the metaphors of the pandemic, the communicative form of official information for 120 days and the recovery of some narratives are recovered published by the national press. The central axis is to work with different communication nuclei such as: governmental, social, environmental and health. One of the main findings is that the official communication of these initial months, backed by some public policies, contained the accelerated growth of the massive contagion, but they were insufficient according to the people's account.

Keywords: pandemic and communication, categories and metaphors, health communication, environmental crisis.

\section{INTRODUCCIÓN}

La crisis ambiental es cada vez más innegable y omnipresente. El año 2020 quedará en la historia como el primer año en que el confinamiento de la especie humana a escala planetaria fue necesario ante la presencia de un problema de salud: el virus (SARS-CoV-2, conocido como coviD-19) para el cual la humanidad no tenía respuesta sanitaria. La amenaza ambiental para la especie humana se concretó en un agente de tipo infeccioso (virus) que, dadas las condiciones de globalización, se volvió incontenible en su propagación y letalidad. La civilización detuvo su 
paso orgulloso, hedonista, y acelerado. Quedó recluida y con urgencia de políticas públicas obligatorias en la mayoría de los países del orbe. La incertidumbre, el miedo y el repliegue dominó el escenario planetario. La libertad, para la mayoría, un valor irrenunciable, quedó postergada, en pausa (Caparroz, 2020).

Los síntomas de esta crisis civilizatoria-ambiental no tienen un culpable y sí un responsable; la culpa no es microscópica o trasmisible, occidental u oriental, de economías desarrolladas o países pobres; la crisis, que incluye la pandemia, está generada por un estilo de crecimiento económico y un estilo de vida que no toma en cuenta los tiempos de recuperación y la capacidad de carga de los ecosistemas. Este entramado fue investigado y anunciado, durante décadas, por los teóricos de la ecología política (Toledo, 1985; Leff, 1986; Martínez Alier, 1991) que persistieron, con fundamentos científicos, a hacer un llamado urgente a la acción pero pocos quisieron escuchar.

En México, en este mismo contexto, el 3 de enero de 2019, durante la presentación del Plan Nacional de Desarrollo en Morelia, Michoacán, Andrés Manuel López Obrador, actual presidente de México (2018-2024), dijo una frase tajante con respecto al Sistema Nacional de Salud:

Tenemos que garantizar el derecho a la salud pensando en todo el pueblo para hacer valer que se cumpla lo que está en el Art. 4 de la Constitución Política de los Estados Unidos Mexicanos. Es el objetivo y todo un desafío convertir en realidad este principio porque se abandonó el sistema de salud pública en los últimos tiempos al grado que está peor que el sistema educativo ( López Obrador, 2019).

La analogía no beneficia en nada al sistema educativo. Más bien la sentencia describe las insuficiencias de la atención médica y la protección de la salud en nuestro país. Son muchos los retos para el sistema de salud, de los que ya se hablado por largo tiempo: la cobertura, la calidad, eficiencia, eficacia y calidez en la atención de los servicios de salud.

El objetivo del presente trabajo es analizar la comunicación en la pandemia, en un contexto de crisis ambiental. Por la complejidad del fenómeno el trabajo relaciona los corpus científicos de al menos cuatro disciplinas: la comunicación, las ciencias ambientales, la salud pública y el análisis discursivo. La relevancia consiste en el enfoque multidisciplinario que rompe el disciplinar y es hacia donde se encamina la comunicación. Encontrar entre los fragmentos disciplinares afinidades que integren la comunicación (Waisbord, 2017, p. 102). El problema 
central de la investigación es dar cuenta de: ¿Cómo se comunicó la pandemia en México desde la versión oficial y si esta forma comunicativa se ancló en una realidad social con múltiples adversidades? ¿A qué modelo de comunicación se apostó en los primeros cuatro meses? Nuestra tesis es que ante un fenómeno de tal magnitud la comunicación pública oficial intentó contener un contagio mayor, que en términos sanitarios sería desastroso, pero ante la situación de crisis social, económica y de salud prevaleciente en nuestro país el resultado fue insuficiente. Los argumentos se desglosan a lo largo de los apartados.

Utilizamos la metáfora como analogía y categoría cualitativa que organiza y estructura lógicamente un discurso. También usamos las generaciones de los modelos de comunicación en salud. Las cinco metáforas son: el miedo, la reclusión, la incertidumbre, la pandemia como guerra y la nueva normalidad. Los modelos de comunicación en salud describen teóricamente una evolución en los últimos sesenta años, por lo que los nombramos generaciones.

Posteriormente, en la fase de resultados, describimos la comunicación oficial resumida en la conferencia de prensa diaria y declaraciones que contratamos con algunas narrativas sobre cómo vive la gente la pandemia documentada en la prensa y sitios web informativos de impacto nacional. Se discuten estas dos versiones contra las generaciones de modelos de comunicación y se arriba a conclusiones. Un principal hallazgo es que trabajar el hecho complejo de una pandemia desde la comunicación es posible si se auxilia de una visión interdisciplinaria. Otro es que la comunicación integral y participativa todavía es una meta.

\section{INVESTIGACIONES SOBRE COMUNICACIÓN AMBIENTAL, PANDEMIAS, CAMBIO SOCIAL Y JUSTICIA}

En investigaciones que relacionan la comunicación, las pandemias y el desarrollo sustentable encontramos el trabajo de Servaes, J. (2012) Comunicación para el desarrollo sostenible y el cambio social. Una visión general en el que se revisan los avances teóricos en la perspectiva de comunicación para el desarrollo a nivel general y que han pasado por el estudio de modernización, dependencia, enfoque de multiplicidad; y en las teorías de la comunicación; en las que está presente el debate entre hacer difusión o propiciar la participación. De igual forma se sintetiza una evaluación histórica del debate en investigación durante las últimas décadas. La investigación arrojó que distintas teorías y metodologías han evolucionado hacia 
una visión más participativa y democrática de la comunicación para la comprensión del desarrollo y una mejora de los niveles de bienestar comunitarios. En la misma línea de comunicación para el desarrollo ubicamos el trabajo de Alejandro Barranquero (2012). De la comunicación para el desarrollo a la justicia eco-social y el buen vivir en que se propone una transformación incorporando un enfoque interdisciplinario, una visión crítica relacionada con problemas ambientales y de salud, una investigación de comunicación para cambio social entendida como un diálogo público y el avance de ésta hacia propuestas de justicia ecológica y buen vivir.

En relación con la comunicación y las pandemias se encuentra la investigación de Huníades Urbina-Medina, et. al. (2016), Comunicación efectiva y ética en casos de epidemias y pandemias en la que se analizan las estrategias de comunicación en salud pública. Particularmente en el caso de la pandemia, se afirma que la comunicación es un proceso interactivo de intercambio de información y opinión entre personas, grupos e instituciones que incluye múltiples mensajes como: riesgo sobre el brote epidémico y la gestión del riesgo incluyendo el contexto de la difusión digital.

Sobre comunicación y protección del entorno se tomó el trabajo documental de Román, C. y Cuesta, O. (2016). Comunicación y conservación ambiental: avances y retos en Hispanoamérica, donde se hace un estudio consultando 70 fuentes entre libros, artículos científicos y bases de datos científicos concluyendo que la comunicación ambiental tiene un sesgo discursivo catastrofista y que la comunicación tendrá que ser más educativa y transformadora.

Los trabajos sobre la comunicación, salud y ambiente, como se puede observar, son interdisciplinarios y transitan hacia una visión de participación, educación, justicia , equidad y democracia, quebrantando los enfoques verticales y mecánicos de esta disciplina.

\section{ELEMENTOS CONTEXTUALES}

La epidemiología es la aplicación del método científico experimental al estudio de una enfermedad sea de origen genético, infeccioso, degenerativo, o cualquier. Una epidemia es la ocurrencia de una enfermedad en un grupo de personas. (Guerrero, R., González, C., \& Medina, E., 1990, p.12) y una pandemia es, por lo tanto, una epidemia de amplitud excepcional que va más allá de una región o comunidad; puede abarcar un país, continente o al mundo (Galván, F., 2012, p. 167). 
Una herramienta fundamental en las epidemias y las pandemias es la comunicación para la salud, entendida como "el uso y el estudio de las estrategias de comunicación para informar e influir sobre decisiones individuales y colectivas que mejoran la salud" (Instituto Nacional del Cáncer de Estados Unidos de Norteamérica, 2004, pp. 2-3).

Se tiene registro que desde el año 1173, 300 epidemias de una enfermedad similar a la influenza han ocurrido con un intervalo promedio de 2,4 años. También se registraron durante la evolución de los viajes y del comercio intercontinental después de 1492 y cuando apareció la primera pandemia conocida de influenza, originada en Asia en 1580. En los tres siglos siguientes se tienen registradas 22, siendo la de 1889 la más letal y grave, similar a la de1918-1919 (Martínez \& Meléndez, 2007, p. 287), aunque esta última, en números absolutos de víctimas humanas, no tiene precedentes históricos. Desde finales del siglo XIX se registraron cinco grandes pandemias en los años 1890,1900, 1918, 1957 y 1968. Está última tuvo su origen en Hong-Kong (Martínez \& Meléndez, 2007, p. 289).

La Organización Mundial de la Salud (OMS) advirtió la evolución de una pandemia de gripa desde hace más de tres lustros; un virus con un origen en las aves, $\mathrm{H}_{5}$ N1, había infectado a más de 241 humanos en nueve países asiáticos y dos africanos, con una tasa de letalidad de más de $50 \%$. Una vez el virus tenga la capacidad de transmisión de humano a humano -advirtieron- en un mundo globalizado, la enfermedad puede alcanzar todos los continentes en menos de tres meses, estimándose entre 2 a 7.4 millones las muertes posibles (Martínez, Manrique \& Meléndez, 2007, p. 291).

El coronavirus (síndrome respiratorio agudo severo, sArs, por sus siglas en inglés) es el virus pronosticado que se fue incubando y gestando del 2004 al 2019 y cuya última mutación es la covid-19. Son virus que pueden estar presentes en animales y humanos, y los organismos afectados tienden a desarrollar resistencia, lo cual genera que el virus mute nuevamente y sea altamente letal. El factor fundamental es la destrucción de los hábitats de las especies silvestres y la invasión de éstos por el crecimiento urbano y la agropecuaria industrial, particularmente la cría industrial principalmente de aves, cerdos y vacas. Más de $70 \%$ de antibióticos a escala global se usan para engorde o prevención de infecciones en animales no enfermos, lo cual ha producido un gravísimo problema de resistencia a los antibióticos, también para los humanos. La oms llamó desde 2017 a que estás industrias dejen de utilizar sistemáticamente antibióticos para estimular el crecimiento de animales sanos (Ribeiro, 2020). 
El proceso de deterioro ambiental y el impacto humano detonará otras pandemias. Simplemente, la pérdida de bosques lleva a un proceso de defaunación, desertización y desaparición de especies de fauna mayor que favorecen la proliferación de roedores que pueden ser portadores de virus (Dirzo, 2020, p. 31).

La destrucción de los ecosistemas y la producción industrial de alimentos como causas de la pandemia son elementos de la crisis ambiental. En las últimas décadas es evidente la degradación de la naturaleza debido a las formas de desarrollo: pesca excesiva, erosión de suelos, reducción de agua potable, consumo insostenible y pérdidas de ecosistemas. La generación de alimentos y energía son demandas que generan los dos elementos centrales del cambio ambiental global: el cambio climático y la pérdida de ecosistemas y biodiversidad (Sarukhán, 2020, p. 16).

Aunado a esto, tenemos los grandes problemas de salud en México. Hace veinte años comenzó una transición epidemiológica de morbilidad y mortalidad en las que enfermedades infecciosas (parásitos e infecciones en el aparato digestivo o respiratorio) adquirieron carácter de crónico degenerativas: enfermedades del corazón, diabetes mellitus, hipertensión y tumores malignos (INEGI, 2020). La mayoría de las anteriores son asociadas a problemas alimenticios (sobre industrialización, saturados en grasas, azucares, sal y calorías) y a un estilo de vida de escasa cultura física.

México atraviesa graves problemas de pobreza, desigualdad, violencia y polarización política que se intensifica en los procesos electorales, variables intervinientes en la condición actual.

Otro grave problema son las condiciones en las que se encuentra el sistema de salud en nuestro país donde la población es atendida por diferentes nichos institucionales. Este sistema ha demostrado ser inequitativo, ineficiente e insensible. Es evidente la falta de inversión necesaria y suficiente para la creación de especialistas médicos, de infraestructura, equipamiento e innovación tecnológica. Lo anterior da niveles de calidad diferenciados y desiguales para los distintos segmentos de la estratificación social, incluso dentro del sector público (Frenk, 2014).

De la misma forma, una pandemia es un problema de salud pública. Julio Frenk (2003) distingue cinco connotaciones de la salud pública: 1) acciones que debe generar el gobierno; 2) promoción de la salud del gobierno en conjunción con la comunidad organizada; 3) servicios no personales como el saneamiento ambiental o programas de salud; 4) acción preventiva a grupos vulnerables, y 5) padeci- 
mientos de alta frecuencia o peligrosidad (p.120). Es notable como en todas estas connotaciones la implicación actual de la pandemia es ineludible.

\section{ELEMENTOS TEÓRICOS}

Usamos como categorías científicas las metáforas. Posibilitan perforar los estratos más superficiales del discurso para acceder a lo no dicho en el mismo: sus presupuestos culturales o ideológicos, sus estrategias persuasivas, sus contradicciones o incoherencias, los intereses en juego, las solidaridades, el valor simbólico y los conflictos latentes. Es un método fundado en la analogía como analizador socio-metafórico, categorías comprendidas a modo de entidades y movimientos metafóricos constitutivamente sociales (Lazcano, 1999, p. 30).

Dado que se investiga cómo se comunica la epidemia, seguimos las historias de los modelos comunicativos en salud. Rodríguez y Ramírez (2010) encontraron que, en la comunicación para la salud, han existido tres modelos de comunicación, que se pueden ubicar generacionalmente:

1. La primera generación opera bajo un esquema de filosofía positivista por su énfasis en el proceso salud enfermedad entendido como la constitución de realidades naturales, verificables, cuantificables y reproducibles que se pueden enunciar mediante leyes universales libres de valores (Navarro, 1997, p. 504). Este enfoque supone que una sociedad informada será una sociedad sana, dado que la transmisión de información genera conciencia, y ésta a su vez conduce a la acción, traducida en términos de prevención, o bien de control de las enfermedades. La fuente asume saber cuál es la información conveniente para el receptor y éste deberá adoptarla sin mayor cuestionamiento, suponiendo que la fuente es experta y se dirige a quienes no tendrían nada que aportar al logro de los objetivos. Estos modelos dominaron teóricamente a partir de mediados de la década de los sesenta hasta los primeros años de los ochenta del siglo pasado.

2. La segunda generación mantiene una línea científica positivista centrada en la transmisión unilateral de conocimientos aunque con un enfoque orientado a la motivación, al desarrollo de habilidades personales y a la autoestima necesarias para la consecución de los objetivos que, en esta segunda etapa, son conductuales apoyándose con campañas en medios y en centros 
de salud; es decir, el énfasis se encuentra en la modificación de hábitos personales, es entonces cuando se abre el discurso de los factores sociales y culturales y el análisis de las motivaciones y resistencias, así como de los instrumentos educativos y persuasivos necesarios bajo el cambio. Esta generación surge con la irrupción de la preocupación ambiental en los años setenta y se desarrolla en las últimas dos décadas del siglo xx (Rogers, 1976, p. 130).

3. La tercera generación, ya en el siglo XXI, tiene un enfoque interaccionista $y$ de diálogo. Supone que la prevención y control de las enfermedades es un asunto del dominio público, no individual. De la antigua postura directiva y unilateral, entramos a una de entendimiento de la cultura y a partir ahí, de negociación y construcción compartida, lo que genera mayor compromiso, integralidad y adopción de actitudes y conductas requeridas en materia de salud y de prevención de la enfermedad considerando los factores específicos de la sociedad. En pocas palabras, son a los sujetos, a quienes se dirigen los esfuerzos comunicativos, quienes decidirán qué acciones emprenderán para la consecución de los objetivos. En este sentido se trata de una opción democrática, directa y muy participativa, donde no hay fuente y receptor, sino que ambas partes cumplen ambos roles, ambas son fuente y receptor en el proceso (Toro, 2001, p. 41).

Por otra parte, se trabajarán cinco metáforas con las que se intenta describir la pandemia: miedo, reclusión, incertidumbre, guerra y nueva normalidad.

\section{CINCO METÁFORAS}

Se usan ejemplos de referencias que sintetizan discursivamente las metáforas de la pandemia, que son las siguientes:

a) El miedo. Argumentos: La irrupción del coronavirus SARS-CoV-2 evidenció en pocas semanas las mayores debilidades y fragilidades de la humanidad (Sorhuet, 2020). Este tipo de virus es de transmisión humana, no tiene vacuna, y es letal. Los contagios y muertes serán miles, ante lo que se tiene impotencia. El miedo también es a la rección a la situación económica y el desempleo. Para los sistemas de salud es un problema añadido; se depende de las condiciones previas de los mismos y la posibilidad real de ser desbordados. 
b) La reclusión. Argumentos: El confinamiento de la humanidad es indispensable para enfrentar la pandemia. La política pública que desde finales de febrero se extendió al planeta: quedarse en casa. Evitar el contagio. No estar cerca y en contacto es pensar en el otro y en cada persona. La libertad de circulación es restringida.

c) La incertidumbre. Argumentos: Esta es la primera pandemia de la humanidad globalizada. Parafraseando la analogía de Morin (2003) navegamos en un océano más grande de incertidumbres con un archipiélago pequeño de certezas. En la condición actual, ante un hecho de dimensiones planetarias, se han originado dos fenómenos recurrentes que se han desbordado en la cuarentena de la humanidad: las informaciones falsas y el uso de las redes digitales para su propagación. A este fenómeno se le ha llamado infodemia (OMS, 2020).

d) La pandemia como guerra. Argumentos: el problema sanitario mundial genera recorte a las libertades civiles y políticas en condiciones de crisis económica, combinada con la militarización, aumenta el retroceso de libertades en las naciones. En sociedades fragmentadas donde prima el individualismo y los avances tecnológicos, la primera medida de quedarse en casa ha sido precedente de otras como la militarización y el endurecimiento de sistemas policiacos y el uso de tecnología para accesos y seguimiento de los ciudadanos (Arkonda, 2020). También el papa Francisco (2020) ha usado esta analogía: "Si la lucha contra el nuevo coronavirus es una guerra, ustedes son un verdadero ejército invisible que pelea en las más peligrosas trincheras. Un ejército sin más arma que la solidaridad, la esperanza y el sentido de la comunidad que reverdece en estos días en los que nadie se salva solo".

e) La nueva normalidad. Argumentos: Reconstrucción verde tras el coronavirus. Principal expositora mundial, Angela Merkel, primera ministra alemana: "Si queremos que esta recuperación sea sostenible, si nuestro mundo debe transformarse para ser más resiliente, tenemos que hacer todo lo que podamos para promover una recuperación verde" (Merkel, 2020). Los poderes saben que esta pandemia proviene de los desequilibrios ecológicos y biológicos de la civilización industrial y la permanencia de la especie humana dependerá de los cambios radicales en el estilo de desarrollo (Toledo, 2020). 


\section{METODOLOGÍA}

Se analizan discursivamente dos tipos de comunicación: la forma en que el gobierno informó durante más de ciento veinte días (marzo-junio del 2020), describiendo la estrategia comunicativa y destacando la estructura de la conferencia de prensa diaria y algunas declaraciones de actores públicos y, desde un enfoque cualitativo, se recuperarán ejemplos documentados en la prensa digital e impresa para obtener un panorama de la base social y sus vivencias con la pandemia. En los resultados se contrastará contra los modelos de comunicación para la salud.

El procedimiento consistió en tres momentos:

1. Descripción de la conferencia de prensa diaria. En la comunicación sobre datos estadísticos en el avance y la contención de la epidemia se realizó y privilegio por esta vía, por parte del gobierno federal por lo que se presenta un resumen de esta, así como un análisis de resultados. Es un registro histórico sintetizado, que después del corte de esta investigación se fue modificando.

2. Se presenta un cuadro sobre las metáforas que sintetiza y da ejemplos sobre declaraciones de funcionarios públicos y los intenta contrastar con declaraciones de personas de la sociedad civil y sus percepciones y sentimientos ante el fenómeno. En cada ejemplo de se da cuenta del modelo de comunicación para la salud.

3. En los resultados se analizan estos dos momentos y se vinculan con los modelos de comunicación para la salud.

\section{RESULTADOS}

\section{Observación y descripción de la conferencia de prensa diaria del gobierno federal}

\section{La apuesta comunicativa del gobierno federal}

La difusión de la información del gobierno federal sobre el avance y medidas de contención de la pandemia fue múltiple: campaña en medios de comunicación y redes sociales, carteles, folletos, sitio web, banners, chat, teléfono, aplicaciones, 
etc. Sin embargo, se utilizó en forma central la información directa por televisión, por emisoras públicas (no cadena nacional) y pocas estaciones públicas de radio. En esta conferencia, aparte de datos numéricos sobre la pandemia y sus efectos en México, se comunica lo que la población debe y puede hacer en el confinamiento.

El gobierno federal utilizó funcionarios públicos del tercer y cuarto nivel de gobierno (subsecretario y directores generales) principalmente del sector salud y considerados como expertos en salud para dar la cara. Ha sido permanente desde marzo hasta la fecha.

El inicio de la estrategia divulgó un solo mensaje: quédate en casa. Este comunicado se trató de forma fundamentada en argumentos cuantitativos sobre la reducción del contagio, al no haber proximidad física.

\section{El escenario}

La conferencia se realiza en Palacio Nacional, en una sala habilitada por la actual Administración Pública Federal para el comunicado matutino diario del presidente de la República.

Está dispuesto un largo escritorio de madera, con el número de micrófonos de los que tomarán la palabra. En la escenografía (o back) está una bandera de México, un letrero con "conferencia de prensa" y una pantalla donde se pasan las diapositivas, en las que antes y después de la conferencia está el logotipo de la campaña de información: el corazón con techo y la frase "Quédate en casa". Domina el color vino y blanco. Hay un escudo nacional diluido y un recuadro con traducción al lenguaje de débiles auditivos.

Al frente de la mesa que preside el evento están dispuestas sillas para los representantes de los medios de comunicación. Son pocas sillas y con frecuencia, al pasar de los días, se notan algunas vacías. Atrás de éstas se encuentran las cámaras. Los periodistas se auxilian de notas en libretas y celulares en el momento de las preguntas.

\section{El formato}

El horario de transmisión es de 19 a 20 horas. La puntualidad al inicio y al final es una de sus características. El formato es de una conferencia de prensa dada por científicos. Consta de dos momentos: el informe sobre los datos del avance de la pandemia en México y en el mundo, y una parte de intercambio de preguntas y 
respuestas. Puede haber un invitado que amplía información específica: puede ser desde el secretario de educación, hasta encargados de la ciencia o de institutos de salud.

Es notable que no están representadas con un reportero las grandes cadenas televisivas o de radiodifusión nacional, tampoco la mayoría de los periódicos de circulación nacional.

El formato no es distinto de la manera establecida por la presidencia. Es una conferencia de científicos que son funcionarios en la actual administración esforzándose por divulgar la situación de la epidemia en el país.

\section{La información y el contenido}

Aunque el tono es de divulgación, la comunicación recupera términos de salud, salud pública y epidemiología para poner en común el impacto de la pandemia.

Lo que se presentó diariamente fue la actualización de los datos del avance de la pandemia a nivel mundial, nacional y estatal.

Comienza con una breve introducción del subsecretario de Prevención y Promoción de la Salud, Dr. Hugo Lopez Gatell Ramírez, que le da el uso del micrófono al Dr. José Luis Alomía Zegarra, que presenta el informe diario. Son datos cuantitativos representados con gráficas circulares, barras, histogramas, curvas de pronósticos, y mapas con los estados de la República mexicana y cuyos contenidos son:

- Casos confirmados activos por región según la oms (el único internacional).

- Seis categorías de la pandemia donde actualizan los datos cada día: casos confirmados, sospechosos activos, activos, defunciones y personas estudiadas.

- Mapa de confirmados activos por entidad federativa.

- Defunciones acumuladas confirmadas de Covid-19, por fecha y entidad federativa.

- Casos sospechosos y confirmados por entidad federativa.

- Casos confirmados por entidad federativa.

- Combinación de casos sospechosos y activos por entidad federativa.

- Defunciones notificadas y confirmadas de la epidemia en las últimas 24 horas. 
- Ocupación hospitalaria de camas y camas con ventilador, por entidad federativa.

- Puede haber otros temas o diapositivas, como la movilidad de la gente en los estados de la República o la situación de los servidores de salud. Después del 1 de junio de 2020 se incluyó un semáforo, la primera semana de tres colores y la segunda se añade un cuarto (rojo, anaranjado, amarillo y verde), que significaban un regreso paulatino a la nueva normalidad, por entidad federativa bajo el reconocimiento de que no había un solo tipo de tiempo y manifestación de la pandemia, sino distintos, por las dimensiones del país y las concentraciones de habitantes en núcleos urbanos.

\section{Los propósitos generales de la conferencia}

Los objetivos explícitos de la estrategia de comunicación y de las acciones públicas del confinamiento por el gobierno federal, dichos al inicio de la epidemia y que fueron retirados, en distintas conferencias fueron:

1. Postergar en el tiempo los efectos cuantitativos (número de contagios activos y su letalidad) de los enfermos de covid-19, dada la imposibilidad de atención sanitaria hospitalaria si presentaban muchos casos simultáneos;

2. Evitar que se produjeran casos un mismo día, ante la sospecha fundada del desbordamiento de los sistemas de salud, y;

3. Redistribución de las capacidades hospitalarias a nivel nacional en los hospitales, según fuera expandiéndose el fenómeno.

\section{Cómo se declara desde el gobierno y se comunica desde abajo la pandemia: los dos frentes comunicativos y el modelo de comunicación asociado}

Para contrastar, reproducimos en el siguiente cuadro dos visiones comunicativas de la pandemia; en primer lugar, colocamos frases de funcionarios del gobierno federal que refieren las analogías, y en un segundo recuadro algunos ejemplos narrativos de cómo la gente vivió la pandemia en los primeros 120 días. Se recuperan relatos de familiares de pacientes y personas que brindaban ayuda, publicados en la prensa nacional. En ambas se citan cómo lo comunicaron algunos medios, 
principalmente impresos. Las ubicamos en las metáforas, aunque algunas frases podrían caber en varias categorías. Al final de cada frase colocamos el modelo de comunicación para la salud al cual se le asocia.

\section{Ejemplos de narraciones de dos visiones de la pandemia y generación de modelo de comunicación en salud}

\begin{tabular}{|c|c|c|}
\hline METÁFORA & $\begin{array}{l}\text { COMUNICACIÓN } \\
\text { DEL GOBIERNO FEDERAL }\end{array}$ & COMUNICACIÓN DE LA GENTE \\
\hline \multirow[t]{2}{*}{ El miedo } & $\begin{array}{l}\text { Para López Obrador, el confinamiento y el miedo } \\
\text { son un asunto de responsabilidad personal: } \\
\text { "Tenemos que vencer no solo la pandemia sino } \\
\text { también nuestros temores, nuestros miedos, } \\
\text { desde luego con cuidado. Lo primero es la salud } \\
\text { y cuidarnos" (Urrutia y Muñoz, 2020a, p. 2). }\end{array}$ & $\begin{array}{l}\text { El miedo ante la falta de educación y } \\
\text { suministro médicos. Susana Rosas, familiar } \\
\text { de un enfermo hospitalizado en el Instituto } \\
\text { Nacional de Enfermedades Respiratorias, } \\
\text { señala: "Si es que se llegara a propagar más } \\
\text { no siento que estamos preparados para lo que } \\
\text { viene, puesto que en los hospitales hay falta } \\
\text { de insumos, no hay educación. No siento que } \\
\text { estemos preparados" (Cortés, 2020). }\end{array}$ \\
\hline & $\begin{array}{l}\text { Modelo de comunicación de segunda } \\
\text { generación }\end{array}$ & $\begin{array}{l}\text { Modelo de comunicación de primera } \\
\text { generación }\end{array}$ \\
\hline \multirow[t]{2}{*}{ La reclusión } & $\begin{array}{l}\text { En la Jornada Nacional de Sana distancia, en los } \\
\text { primeros meses de la pandemia, López Gatell } \\
\text { insistió en la importancia del confinamiento: } \\
\text { "Todas y todos debemos cuidarnos a nosotros } \\
\text { mismos, pero también debemos contribuir } \\
\text { para que logremos reducir la intensidad de esta } \\
\text { epidemia. En la medida en que logremos las } \\
\text { medidas masivas de inmovilización, de reducir } \\
\text { la actividad laboral en forma masiva, tendremos } \\
\text { un beneficio para todas y todos y el beneficio es } \\
\text { reducir la velocidad de transmisión de este virus" } \\
\text { (López Gatell, 2020, blog, Gobierno de México). }\end{array}$ & $\begin{array}{l}\text { El confinamiento desata casos de angustia } \\
\text { y ansiedad, señala Luis Monrroy, durante } \\
\text { el aislamiento en los hogares: "La cantidad } \\
\text { de información negativa que recibimos nos } \\
\text { detona mayor ansiedad. Los conteos diarios de } \\
\text { víctimas en todo el mundo, el estado de alerta } \\
\text { permanente, toda la información que te llega a } \\
\text { través de redes sociales y la televisión te afecta } \\
\text { y te hace pensar en que te puedes contagiar" } \\
\text { (Barragán \& Rodríguez, 2020). }\end{array}$ \\
\hline & $\begin{array}{l}\text { Modelo de comunicación de segunda } \\
\text { generación }\end{array}$ & $\begin{array}{l}\text { Modelo de comunicación de primera } \\
\text { generación }\end{array}$ \\
\hline
\end{tabular}




\begin{tabular}{|c|c|c|}
\hline \multirow[t]{2}{*}{$\begin{array}{l}\text { La } \\
\text { incertidumbre }\end{array}$} & $\begin{array}{l}\text { Sobre todo, por la presión económica el esfuerzo } \\
\text { del gobierno federal fue generar certidumbre, } \\
\text { Lopez Gatell declara: "No podemos quedarnos } \\
\text { sin mover y menos durante tres años" (Cruz, } \\
\text { 2020, p. 3). }\end{array}$ & $\begin{array}{l}\text { La incertidumbre ante la falta de cuidados en } \\
\text { la atención médica, Anayeli Castillo señala: "Yo } \\
\text { digo que no es la (actuación) correcta. Ahorita } \\
\text { al paciente que tienen aquí lo tienen aislado, } \\
\text { pero entras y ahí adentro no usan cubrebocas } \\
\text { los doctores ni las enfermeras, nada. No me da } \\
\text { tranquilidad" (Cortés, 2020). } \\
\text { Las dudas por desinformación y falta de } \\
\text { atención en la línea COVID-19. Un familiar } \\
\text { asegura: "Nosotros tampoco sabíamos qué } \\
\text { estaba pasando. Si en la línea (telefónica) nos } \\
\text { decían que no, aunque él se sentía mal, nos } \\
\text { daba miedo ir al hospital porque qué tal que } \\
\text { no tenía nada y ahí lo íbamos a agarrar (al } \\
\text { coronavirus)" (Rodríguez, 2020, p. 12). }\end{array}$ \\
\hline & $\begin{array}{l}\text { Modelo de comunicación de primera } \\
\text { generación }\end{array}$ & $\begin{array}{l}\text { Modelo de comunicación de primera } \\
\text { generación }\end{array}$ \\
\hline \multirow[t]{2}{*}{$\begin{array}{l}\text { La pandemia } \\
\text { como guerra }\end{array}$} & $\begin{array}{l}\text { El canciller mexicano Marcelo Ebrard usó la } \\
\text { metáfora para hablar de acuerdos globales } \\
\text { como estrategias para evitar una "guerra" } \\
\text { internacional de insumos y equipamiento } \\
\text { médico, por lo que "el presidente López Obrador, } \\
\text { solicitó en la reunión del G-20, y lo haremos } \\
\text { la próxima semana en Naciones Unidas, para } \\
\text { que sea este organismo multinacional el que } \\
\text { regule que ningún país busque concentrar estos } \\
\text { insumos" (Poy, 2020, p. 3). }\end{array}$ & $\begin{array}{l}\text { El presidente de Caritas mexicana, Rogelio } \\
\text { Narváez Martínez, describe las llamadas al } \\
\text { centro de atención telefónica, habilitado para } \\
\text { brindar ayuda, sobre todo alimenticia o apoyo } \\
\text { emocional: "Ya fuimos rebasados. Estamos al } \\
\text { tope. Tendremos que abrir otras } 30 \text { líneas y } \\
\text { preparar más voluntarios. El } 90 \% \text { de la gente } \\
\text { habla para pedir alimento; el resto es gente } \\
\text { que nos habla para ofrecernos una donación o } \\
\text { son personas desesperadas que sólo quieren } \\
\text { ser escuchadas porque ya no aguantan la } \\
\text { situación económica" (Vera, 2020, p. 18). } \\
\text { En los hospitales también se vive una situación } \\
\text { semejante de batalla inacabable, dicen las } \\
\text { enfermeras: "No estamos preparadas para } \\
\text { estos niveles de mortalidad. En mi piso, donde } \\
\text { se puede atender a } 28 \text { pacientes, tenemos } \\
\text { ocupadas } 25 \text { camas, y así como se desocupan, } \\
\text { se vuelven a asignar. Pensábamos que con } \\
\text { el paso del tiempo esto iba a bajar, pero la } \\
\text { llegada de pacientes graves y críticos se ha } \\
\text { mantenido constante. Son muchas semanas de } \\
\text { estar al máximo en el estrés y la angustia" (Poy, } \\
2020, \text { p. 2). }\end{array}$ \\
\hline & $\begin{array}{l}\text { Modelo de comunicación de segunda } \\
\text { generación }\end{array}$ & $\begin{array}{l}\text { Modelo de comunicación de segunda y de } \\
\text { tercera generación }\end{array}$ \\
\hline
\end{tabular}




\begin{tabular}{|l|l|l|}
\hline & $\begin{array}{l}\text { Pocos días antes del fin de la Jornada de } \\
\text { Sana Distancia López Obrador declara, } \\
\text { con relación a la nueva normalidad y del } \\
\text { posible desbordamiento de los servicios de } \\
\text { salud: "Ya tomé la decisión de salir (de gira) } \\
\text { porque necesitamos reiniciar nuestra vida } \\
\text { pública e ir hacia la nueva normalidad con } \\
\text { todos los cuidados (...)Vamos bien, ya se } \\
\text { domó la pandemia, ya se alejó el riesgo de } \\
\text { una saturación en hospitales que hubiese } \\
\text { significado más pérdidas de vidas humanas y } \\
\text { mucho dramatismo, eso afortunadamente ya se } \\
\text { normalidad } \\
\text { superó" (Urrutia \& Méndez, 2020b, p. 2). }\end{array}$ & $\begin{array}{l}\text { Sobre la desinformación, negligencia o } \\
\text { desesperación, Ricardo, del servicio de limpia } \\
\text { de la Ciudad de México, opina el 1 de junio: } \\
\text { "Mucha gente está confundida. Se quedaron } \\
\text { con la idea de que el final de la Jornada } \\
\text { de Sana Distancia era también el final de } \\
\text { quedarse en casa. Y por eso muchos creyeron } \\
\text { que este lunes ya se acabó la pandemia. Oue ya } \\
\text { todo es normal.Y pues ahí tiene el resultado: } \\
\text { mucha gente en la calle y mucho tráfico" } \\
\text { (Ureste \& Sandoval, 2020). }\end{array}$ \\
\cline { 2 - 4 } & $\begin{array}{l}\text { Modelo de comunicación de segunda } \\
\text { generación }\end{array}$ & $\begin{array}{l}\text { Modelo de comunicación de primera } \\
\text { generación }\end{array}$ \\
\hline
\end{tabular}

FUENTE:ELABORACIÓN PROPIA, 2020.

\section{ANÁLISIS Y DISCUSIÓN}

- En la conferencia de prensa y en las declaraciones de los funcionarios encontramos un esfuerzo comunicativo, de aliento y didáctico, por disminuir las metáforas de incertidumbre, guerra o miedo con un discurso claro y usando las herramientas comunicativas y científicas y de datos disponibles. La apuesta televisiva y declarativa fue de disposición más que de penetración: que la población tuviera acceso a los datos e información de lo que estaba pasando. Sin embargo, en la revisión de lo que la prensa recuperó de pacientes, familiares y servidores públicos y privados existe una realidad lejana al discurso oficial y cercana a la realidad del país. Como lo registra el cuadro los modelos de comunicación no llegan a un diálogo e interacción productiva.

- De las otras dos metáforas la insistencia fue de quedarse en casa como posibilidad de contención, de no propagación. Se insistió sobre todo en que la nueva normalidad no sería pronta ni generalizada y que habría que cambiar radicalmente algunos hábitos alimenticios por las epidemias ya desatadas previamente en el país: diabetes, hipertensión y cáncer que fueron asociadas a la pandemia. Las metáforas desde las narrativas opuestas describen la situación de carencia y abandono en que la pandemia tocó a la gente. 
- El modelo de comunicación se mueve de la primera a la segunda generación, en las narrativas. Colaboró la insuficiente interacción con la prensa por no ser reporteros o periodistas especializados en salud. También el desdén de los medios de mayor impacto y circulación. El modelo de comunicación gubernamental es eficiente en el propósito de extender en el tiempo la curva de la pandemia, pero insuficiente al no abarcar necesidades específicas de las personas. Son dos comunicaciones distintas, que dan cuenta de la realidad de la toma de decisiones, y la vía en el conocimiento y percepción de la gente.

- En los meses analizados los propósitos comunicativos del gobierno se cumplen en lo general, sobre todo en términos epidemiológicos. Sin embargo, una pandemia tiene otros factores, como los económicos, sociales, culturales, ambientales y ahora de redes sociales que influyen y afectan esta comunicación. La comunicación de situaciones de riesgo en salud debe ser atendida en forma integral.

\section{CONCLUSIONES}

La interdisciplinariedad es una posibilidad de aproximación científica y compleja a los problemas de la realidad. Es un esfuerzo de ruptura del pensamiento fragmentario. La comunicación para la salud, la ambiental, la política oficial, la histórica económica y el trabajo en los medios de comunicación no pueden ser tratadas como estancos, es necesario recuperar saberes científicos e integrarlos para entender fenómenos como la pandemia. Ese ha sido el esfuerzo de este documento.

Aprendimos que no hemos sabido relacionarnos sustentablemente con la naturaleza y uno de los efectos de lo que se considera una crisis ambiental es la pandemia del 2020. Por eso el artículo se enmarca en ese contexto. La pandemia es solo un síntoma, como lo es el cambio climático, la pérdida de biodiversidad o la desigualdad social. Estás crisis, de salud, económica, educativa y ambiental alcanzan grados de desesperación en las personas que también tienen un discurso que no alcanza a ser escuchado.

Nadie estaba preparado para la pandemia, aunque hubo avisos y síntomas que no se contuvieron a tiempo: en el sector ambiental, de alimentación, salud, económico y agroindustrial. Ya desatada, el gobierno instrumentó una comunicación científica vertical, por medios de comunicación, y declarativa para informar de los 
avances de los contagios y sus efectos. Trató de comunicar los riesgos e insistió en la estrategia de aislamiento y confinamiento para retrasar el avance de esta, el efecto fue positivo por la extensión en el tiempo de los contagios ante un ya limitado y mermado sistema de salud nacional. Sin embargo, la comunicación en cascada no toca o penetra en las realidades de las personas.

Como lo mostramos, los problemas de salud y su comunicación no se agotan en sí mismos. Existen factores que conviven con la pandemia: los efectos en la población como son los casos de personas con nombre y apellido, presiones de poderes en un entorno electoral próximo; lo informados y educados que estén las personas antes de un evento catastrófico y la influencia y el manejo de la comunicación por otras vías.

Las metáforas colaboraron como puntos focales para no extraviarnos en los objetivos de búsqueda y de recuperación de narrativas. Los modelos de comunicación son termómetros con los cuales se hace evidente que una comunicación profunda, dialogada, interactiva, fundada, integral y funcional en salud es todavía distante. La pandemia evidenció carencias, agendas pendientes y lo vulnerable que es una sociedad mundial y nacional ante problemas globales en salud. Es indispensable una comunicación de base, recuperar una educación para la salud en las familias, las escuelas y permanentemente en los medios.

\section{REFERENCIAS}

Arkonda, K. (2020, 1 de mayo). Tecnología y militarización en tiempos del coviD-19. Nodal. https://www.nodal.am/2020/05/tecnologia-y-militarizacion-en-tiempos-delcovid-19-por-katu-arkonada/

Barragán, A., \& Rodríguez, D. (2020). Vivo con ansiedad y estoy en confinamiento; la amenaza invisible durante la cuarentena. El País. https://verne.elpais.com/verne/ 2020/05/08/mexico/1588895035_027100.html

Barranquero, A. ( 2012). De la comunicación para el desarrollo a la justicia ecosocial y el buen vivir. Cuadernos de Información y Comunicación, Universidad Complutense, (17), 63-78. https://doi.org/10.5209/rev_ciyc.2012.v17.39258

Caparrós, M. (2020). Es tanto el temor a morir de CoviD-19, que incluso renunciamos a la libertad. La Jornada, 5 .

Cortés, P. ( 2020, 1 de marzo). La falta de insumos en hospitales genera temor en los mexicanos por el coronavirus. Sinembargo. https://www.sinembargo.mx/01-03$\underline{2020 / 3740071}$ 
Cruz, A. (2020, 15 de junio). Estima SSA que el COVID-19 estará activo tres años. La Jornada, 3.

Dirzo, R. (2020, 3 de junio). Impacto ambiental y Pandemia. Diálogos Naturaleza y Pandemia. Colegio Nacional. En Enciso, A. De continuar el daño al ambiente, otras pandemias volverán a aparecer, 31.

Francisco, papa. (2020, 27 de marzo). Urbe e orbi.

Frenk, J. (2003). La salud de la población. Hacia una nueva salud pública. La ciencia para Todos. Fondo de Cultura Económica, 120.

Frenk, J. (2015). Señalando el camino hacia la cobertura universal de salud: un llamado a la acción. The Lancet, MEDICC Review, (17), 62.

Galván, F. (2012). Diccionario ambiental y de asignaturas afines. Guía para servidores públicos, empresarios y profesionales, comprometidos con la conservación del ambiente. Ediciones Arlequín, p. 167.

Guerrero, R., González, C., \& Medina, E. (1990). Epidemiología. Addison-Wesley Iberoamericana, Colección Ciencias de la Salud, 12.

Instituto Nacional del Cáncer de los Estados Unidos. (2004). Making health communication programs work. https://www.cancer.gov/publications/health-communication/ pink-book.pdf

Instituto Nacional de Estadística, Geografía e Informática (INEGI) (2020). Datos de salud. https://www.inegi.org.mx/temas/saludsat/

Lizcano, E. (1999). La metáfora como analizador social. Revista de Metodología de Ciencias Sociales, (2), 29-60. https://doi.org/10.5944/empiria.2.1999.709

Leff, E. (1986). Ecología y capital: hacia una perspectiva ambiental del desarrollo. Universidad Nacional Autónoma de México, 43-146. https://doi.org/10.24201/edu.v2i3.654

López, A. M. ( 2019). Inauguración de oficinas del IMSS y presentación de Plan IMSS 2018 2024. Versión estenográfica. Morelia, Michoacán. Gobierno de México. Presidencia de la República. https://www.gob.mx/presidencia/articulos/mensaje-del-presidente-andres-manuel-lopez-obrador-durante-inauguracion-de-oficinas-del-imss-y-presentacion-de-plan-imss-2018-2024?idiom=es

López, H. (2020, 28 de marzo). Informe diario sobre coronavirus CoVID-19 en México. Gobierno de México. https://www.gob.mx/presidencia/articulos/version-estenografica-conferencia-de-prensa-informe-diario-sobre-coronavirus-covid-19-en-mexico-239159?idiom $=\mathrm{es}$

Martínez, J. (1991). La Economía y la ecología. Fondo de Cultura Económica.

Martínez, A. Manrique F., \& Melendez, B. (20 07 ). La pandemia de gripa de 1918 en Bogotá. Revista Dynamis, (27), 287-307.

Merkel, A. (2020). Merkel apoya incremento ambicioso de objetivos de protección climática de Unión Europea. http://spanish.xinhuanet.com/2020-04/29/c_139016250.htm

Morin, E. (2003). Educar en la era planetaria. Gedisa, 41. 
Navarro, V. (1997). Donde no hayvisión, el pueblo perece. Organización Mundial de la Salud, Lancet, 504 .

Organización Mundial de la Salud. (2020, 2 de febrero). Contra la desinformación sobre el nuevo coronavirus. El plural. https://www.elplural.com/sociedad/oms-lanza-campana-desinformacion-coronavirus_232449102

Poy, L. (2020, 28 de marzo). Estamos en la última oportunidad de frenar al CoVID-19: López-Gatell. La Jornada, 3.

Poy, L. (2020, 26 de junio). Personal médico exhausto y frustrado. México. La Jornada, 2.

Ribeiro, S. (2020, 29 de febrero). Coronavirus, agronegocios y estado de excepción. $L a$ Jornada, 24.

Rodríguez, A. (2020,10 de mayo). La primera víctima del rascarrabias 911. Proceso (2271), 12.

Rogers, E.M. (1976). Communication and development: Critical Perspectives. Sage, 130.

Rodríguez, O., \& Ramírez, R. (2010). Comunicación para la salud: Notas sobre los modelos de intervención. Revista Educativa Digital Pálido punto de Luz, (1). http://palido.deluz. $\underline{\mathrm{mx} / \mathrm{articulos} / 17}$

Román, C., \& Cuesta, O. (2016). Comunicación y conservación ambiental: avances y retos en Hispanoamérica. Revista Latina de Comunicación Social, (71), 15-39. https://doi. org/10.4185/rlcs-2016-1082

Sarukhán, J. (2020, 4 de junio). Cambio climático y Pandemia. En Diálogos Naturaleza y Pandemia Colegio Nacional. En Enciso, A. Acelera el desarrollo el cambio climático México, La Jornada, 16.

Servaes, J. (2012). Comunicación para el desarrollo sostenible y el cambio social. Una visión general. Cuadernos de Información y Comunicación, (17), 17-40. https://doi. org/10.5209/rev_ciyc.2012.v17.39256

Sorhuet, H. (2020, 8 de abril). Todo cambió. El País.

Toledo, V. (1985). Ecología y autosuficiencia alimentaria. Universidad Nacional Autónoma de México, 15-7.

Toledo, V. (2020, 5 de mayo). La reactivación pos-COVID-19 será ecológica o no será. La Jornada, 26.

Toro, J., \& Rodríguez, M. (2001). La comunicación y la movilización social en la construcción de bienes públicos. Departamento de Integración y Programas Regionales Instituto Interamericano para el Desarrollo Social/Banco Interamericano de Desarrollo, 41.

Ureste, M., \& Sandoval, F. (2020, 2 de junio). Nueva normalidad en CD MX inicia con mucha gente en la calle y tránsito; creen que la pandemia ya acabó. Animal Político.

https://www.animalpolitico.com/2020/06/nueva-normalidad-gente-calle-transito-creen-pandemia-acabo/

Urbina-Medina, H. et. al. (2016). Comunicación efectiva y ética en casos de epidemias y pandemias. Archivos de la Sociedad Venezolana de Puericultura y Pediatría, 79(4), octubre-diciembre, 113-117. 
Urrutia A., \& Muñoz. (2020a, 12 de junio). Confinamiento responsabilidad personal. La Jornada, , 2.

Urrutia A., \& Méndez, E. (2020b, 28 de marzo). Se va AMLo de gira para reactivar la economía. México. La Jornada, 3.

Vera, R. (2020, 10 de mayo). Vamos hacia la hambruna. Proceso (2271), 18.

Waisbord, S. (2017). La comunicación pública: mutaciones e interrogantes. Revista Nueva Sociedad, 269, mayo-junio, 98-109. 